\title{
BMJ Open Central neurobiological effects of physical exercise in individuals with chronic musculoskeletal pain: a systematic review
}

\author{
Rutger M J de Zoete (D) ,1,2 Kenneth Chen, ${ }^{1,3}$ Michele Sterling ${ }^{1}$
}

To cite: de Zoete RMJ, Chen K, Sterling M. Central neurobiological effects of physical exercise in individuals with chronic musculoskeletal pain: a systematic review. BMJ Open 2020;10:e036151. doi:10.1136/ bmjopen-2019-036151

- Prepublication history and additional material for this paper are available online. To view these files, please visit the journal online (http://dx.doi org/10.1136/bmjopen-2019036151).

Received 03 December 2019 Revised 21 April 2020 Accepted 28 May 2020

\section{Check for updates}

(C) Author(s) (or their employer(s)) 2020. Re-use permitted under CC BY-NC. No commercial re-use. See rights and permissions. Published by BMJ.

${ }^{1}$ RECOVER Injury Research Centre, NHMRC Centre of Research Excellence in Recovery Following Road Traffic Injuries, The University of Queensland, Herston, Queensland, Australia ${ }^{2}$ School of Allied Health Science and Practice, The University of Adelaide, Adelaide, South Australia, Australia

${ }^{3}$ Geriatric Education and Research Institute, Singapore

Correspondence to Dr Rutger M J de Zoete; rutger.dezoete@adelaide.edu.au

\section{ABSTRACT}

Objective Primary objectives: to investigate the central neurobiological effects (using MRI) of physical exercise in individuals with chronic pain. Secondary objectives: (1) to investigate the associations between central changes and clinical outcomes and (2) to investigate whether different types and dosages of physical exercise exert different central changes.

Design Systematic review searching four electronic databases up to September 2018: AMED, CINAHL, Embase and MEDLINE. Two reviewers independently assessed the methodological quality of included studies using the Cochrane Collaboration's Risk of Bias in Non-Randomised Studies-I tool. A standardised extraction table was used for data extraction, which was performed by two reviewers. Interventions Studies reporting any physical exercise intervention in any chronic musculoskeletal pain condition were included. Eligibility of 4011 records was screened independently by two reviewers, and four studies were included in the review.

Primary and secondary outcome measures Primary outcome: any brain outcome assessed with any MR technique. Secondary outcomes: any self-reported clinical outcomes, and type and dosage of the exercise intervention.

Results All four studies had high risk of bias. There was heterogeneity between the brain areas studied and the types of exercise interventions delivered. All studies reported functional MRI changes in various brain areas following an exercise intervention. Insufficient data were available to conduct a meta-analysis or to answer the secondary aims.

Conclusions Only a limited number of studies were available and all were at high risk of bias. None of the studies was randomised or included blinded assessment. Exercise may exert effects on brain neurobiology in people with chronic pain. Due to the high risk of bias, future studies should use a randomised study design. Investigation of morphological brain changes could be included.

PROSPERO registration number CRD42018108179.

\section{INTRODUCTION}

Chronic musculoskeletal pain is a burdensome and costly health problem. ${ }^{1}$ Globally, over $20 \%$ of adults ( $\geq 18$ years), and over
Strengths and limitations of this study

- This systematic review investigates the central neurobiological effects of physical exercise assessed with MR techniques, providing information regarding the specific underlying neurobiological mechanisms.

- This study was conducted following the Preferred Reporting Items for Systematic Reviews and MetaAnalyses guidelines.

- Only studies published in English were included, which could lead to missed relevant publications in other languages.

- Only four studies were identified, reporting different outcome measures in relatively small sample sizes, hence meta-analysis was not possible.

- All four included studies were non-randomised studies of low quality.

$33 \%$ of older adults ( $\geq 65$ years), experience chronic pain..$^{2-4}$ Chronic pain is associated with substantial psychological comorbidity, reduced physical function and poor quality of life. ${ }^{5}$ Physical exercise is commonly prescribed for people with chronic pain by first line practitioners, including physiotherapists, medical doctors and chiropractors. ${ }^{6}$ Although exercise is a low-cost, accessible and low-risk therapeutic intervention, the effects on pain and disability for a variety of conditions, including fibromyalgia (FM) ${ }^{7-9}$ complex regional pain syndrome (CRPS), ${ }^{10}$ osteoarthritis ${ }^{11}$ and whiplash-associated disorder (WAD) ${ }^{12}{ }^{13}$ are modest.

Structural and functional brain alterations have been found in chronic musculoskeletal pain conditions. ${ }^{14-16}$ Reduced white and grey matter volume and density ${ }^{17-20}$ have been demonstrated in people with chronic low back pain (LBP) ${ }^{21}{ }^{22} \mathrm{FM}^{23}{ }^{23} \mathrm{WAD}^{24}{ }^{25}$ and nontraumatic neck pain. ${ }^{24}$ Alterations in functional and structural connectivity between different brain areas have been shown in individuals with CRPS, ${ }^{18} \mathrm{FM}^{1923}$ and chronic 
LBP. $^{26}$ Finally, deficient inhibitory pain modulation in patients with WAD has been reported to correlate with cerebral metabolite levels. ${ }^{27}$ Although the relationship is not well understood, some of these brain changes correlate with pain intensity, ${ }^{28}{ }^{29}$ and successful treatment of chronic pain has been associated with a reversal of abnormal brain morphometry. ${ }^{22}$

In non-painful conditions, physical exercise has been shown to exert effects on brain morphology ${ }^{30}$ (eg, volume and density) and function. ${ }^{31}$ In healthy adults and trained athletes, one session of physical exercise increased the functional connectivity between several brain regions. ${ }^{32} 33$ Overweight children who participated in an 8-month exercise intervention showed significant improvements in the spatial refinement of three out of four functional networks. ${ }^{34}$ In athletes, changes in functional activation were found to be associated with decreased pain sensitivity after $120 \mathrm{~min}$ aerobic exercise. ${ }^{33}$

As physical exercise induces brain changes in nonpainful conditions, it is possible that exercise for people with chronic musculoskeletal pain could also influence brain morphology and function, and subsequently improve pain and disability. Exercise does exert certain central effects in people with chronic pain, demonstrated by the effects of exercise on pain thresholds. While in asymptomatic people exercise increases pain thresholds $^{35}$ (exercise-induced hypoalgesia (EIH)), in people with chronic pain the effects of exercise on pain thresholds vary, with a recent review reporting effect sizes between -1.13 and $1.50 .{ }^{35}$ Decreased pain thresholds after exercise (exercise-induced hyperalgesia) have been identified in chronic $\mathrm{WAD}^{36} 37$ and LBP, ${ }^{38}$ however, it does not occur in all patients with chronic pain. ${ }^{35} 39$ The differential effects of exercise on pain thresholds, that is, hypoversus hyperalgesia, represent a central nervous system response. ${ }^{36}$ Rather than using clinical pain assessments, however, investigating brain responses to exercise via MR methods may provide more information regarding the specific underlying neurobiological mechanisms. A better understanding of these mechanisms might provide valuable insight into who might, and who might not, respond positively to exercise interventions, which may improve the effectiveness of neck pain management strategies.

A systematic review found that conservative interventions may induce functional and structural brain changes in prefrontal regions in patients with chronic musculoskeletal pain. ${ }^{40}$ This review included studies of physical, psychological and multidisciplinary interventions, and although physical exercise was part of these, only two exercise studies were identified at the time this review was conducted in 2015. The current systematic review aims to investigate the central neurobiological effects (assessed with MR techniques) of physical exercise in people with chronic musculoskeletal pain. Secondary aims are (1) to investigate the association between central changes and clinical outcomes of pain and disability and (2) to investigate whether there are differences in central changes depending on the type and dosage of the exercise intervention.

\section{METHODS}

This systematic review was conducted following the Preferred Reporting Items for Systematic Reviews and Meta-Analyses guidelines. ${ }^{41}$

\section{Identification of studies}

A search strategy was designed with a medical research librarian and agreed on by all authors. The strategy, consisting of search terms for 'exercise', 'brain' and 'magnetic resonance techniques', was used to search four electronic databases up to September 2018: AMED, CINAHL, Embase and MEDLINE. A standardised search string for exercise was used consistent with a Cochrane systematic review. ${ }^{11}$ Online supplementary appendix 1 provides the search strategy for the database MEDLINE.

Studies were included if they conducted a physical exercise intervention in a chronic pain sample and if they reported outcomes of the human brain assessed with any MR technique. Randomised controlled trials (RCTs), as well as other intervention studies such as non-randomised pre-post designs, were included. Secondary outcomes of interest were self-reported clinical outcomes (such as pain, disability and quality of life) and type and dosage of the exercise intervention. As the effect of type and dosage of exercise intervention is currently unknown, any physical exercise intervention of any duration was included. Studies were excluded if they reported investigations of animals or children ( $<18$ years), or if the full-text article was not available in English.

After duplicates, conference proceedings and articles in a language other than English were removed, records were screened for title and abstract independently by two reviewers. Articles that were deemed potentially eligible for inclusion were downloaded and were subsequently screened for full text independently by two reviewers. Any disagreement on the inclusion of a record in either of the screening stages was resolved through consensus, or alternatively by consulting a third reviewer. For both screening stages, the inter-rater agreement was calculated using Cohen’s kappa ( $\kappa)$.

\section{Data synthesis and analysis}

Data from all included studies were extracted by two reviewers using a data extraction table agreed on by all authors. Extracted data included study details (author, year), methodological details (design, sample size), participant demographics (age, sex, diagnosis), the primary outcomes (any central changes assessed with MR), and the secondary outcomes including any clinical outcomes and the type and dosage of exercise interventions.

\section{Assessment of study characteristics}

Quality assessment of non-randomised studies was performed using-the Cochrane Collaboration's Risk of 


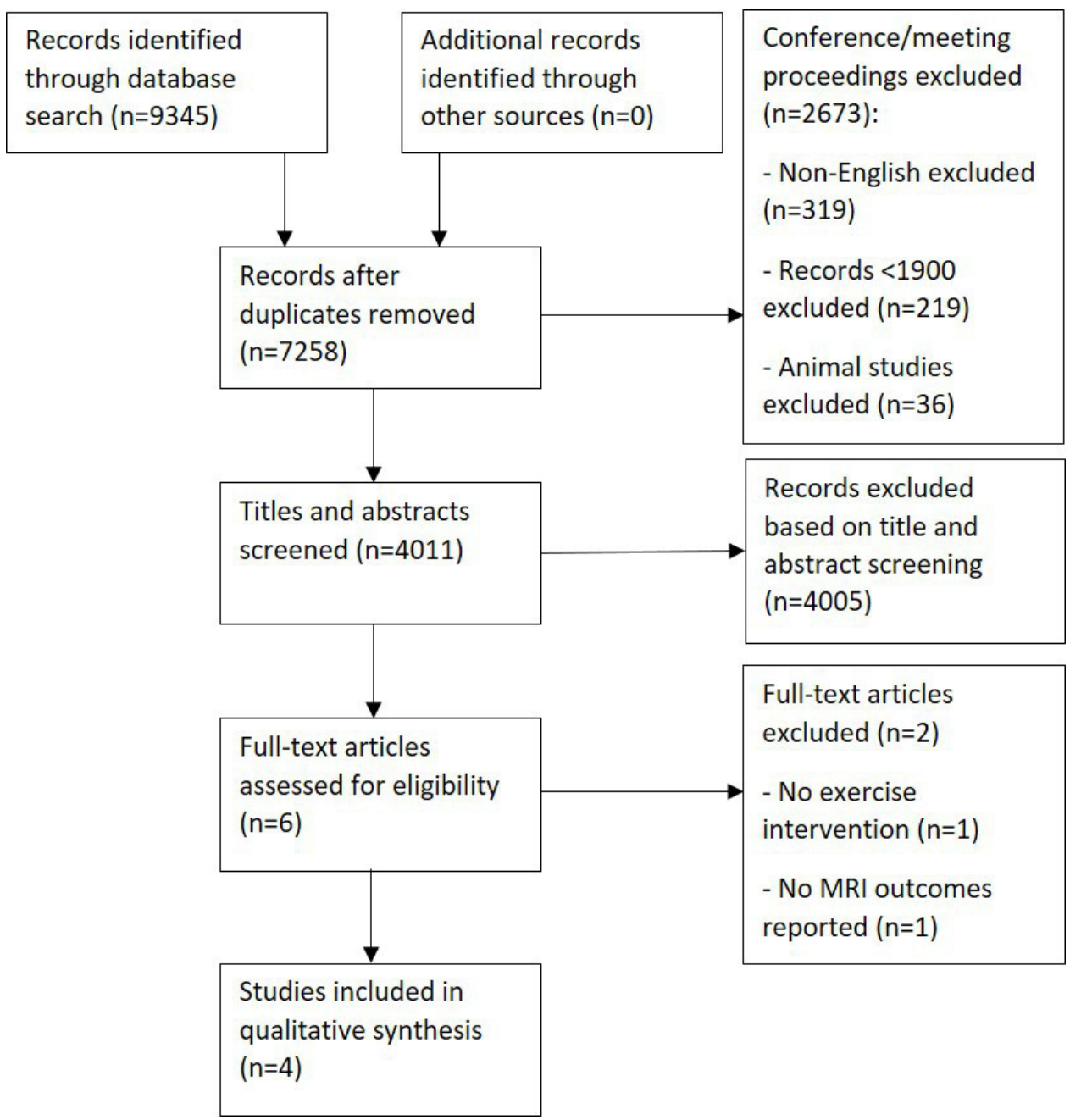

Figure 1 Flow of studies through the review.

Bias In Non-Randomised Studies tool. ${ }^{42}$ Methodological quality was assessed independently by two reviewers and the inter-rater agreement was calculated. Studies were not excluded based on a high risk of bias.

\section{Patient and public involvement}

There was no patient or public involvement in this review.

\section{RESULTS}

\section{Flow of studies through the review}

The electronic database search identified 9345 records. Following the removal of duplicate records, conference proceedings, non-English studies, records from before 1900, and animal studies, 4011 records were screened for title and abstract (figure 1). Records were excluded based on the included participants (not reporting individuals with chronic pain), outcome measures (not reporting an MR assessment of the brain), or due to the treatment not being a physical exercise intervention. Six studies were deemed potentially eligible by the independent screening by two reviewers. After the full-text screening by two reviewers, four articles were included in the systematic review. Studies that were included reported an MR outcome of the brain assessed in individuals with chronic pain, measured before and after a physical exercise intervention. The inter-rater agreement for the title and abstract screening was $\kappa=0.997$ (for chance corrected, weighted kappa $\left.\kappa_{\mathrm{w}}=.727\right)$, and for the full-text screening $\kappa=0.833\left(\kappa_{\mathrm{w}}=.667\right)$.

\section{Characteristics of studies}

The four included studies (table 1) described samples of individuals with FM (Ellingson et $a l^{43} \mathrm{n}=9$, mean age 39; Flodin et al, ${ }^{44} \mathrm{n}=14$, mean age 48; Martinsen et $a l^{45}$ $\mathrm{n}=19$, mean age 50) and a mixed sample including individuals with FM, back pain and CRPS (Micalos et al, ${ }^{46}$ $\mathrm{n}=11$, mean age 50). Two studies ${ }^{44}{ }^{45}$ reported patients' symptom durations of 7 and 8 years, and two studies ${ }^{434}$ did not report pain duration (although one of these ${ }^{46}$ only included patients with pain $>1$ year). The exercise interventions were either one session, ${ }^{43}$ or lasting for $12^{46}$ or $15^{44} 45$ weeks. Exercise regimens included aerobic ${ }^{4346}$ or strengthening ${ }^{44}$ exercises or a combination of aerobic and strengthening exercises. ${ }^{44}$ All studies reported MRI techniques to investigate brain characteristics, including functional MRI (fMRI), resting state fMRI (rs-fMRI) ${ }^{44}$ 
Table 1 Overview of findings from included studies

\begin{tabular}{|c|c|c|c|c|c|}
\hline Study & Sample & MR procedure & MR findings & Clinical measures & $\begin{array}{l}\text { Physical exercise } \\
\text { intervention }\end{array}$ \\
\hline Ellingson et $a l^{43}$ & $\begin{array}{l}\text { Chronic } \\
\text { fibromyalgia, } n=11 \\
\text { (11 female) }\end{array}$ & fMRI & $\begin{array}{l}\text { Exercise-induced } \\
\text { increased activity in } \\
\text { the left dorsolateral } \\
\text { PFC. }\end{array}$ & $\begin{array}{l}\text { MPQ significantly } \\
\text { decreased } \\
\text { postexercise } \\
\text { (Cohen's d=0.39). }\end{array}$ & $\begin{array}{l}\text { One session of aerobic } \\
\text { exercise. One session } \\
\text { of } 25 \text { min moderate } \\
\text { intensity. }\end{array}$ \\
\hline Flodin et al ${ }^{44}$ & $\begin{array}{l}\text { Chronic } \\
\text { fibromyalgia, } n=14 \\
\text { (14 female) }\end{array}$ & $\begin{array}{l}\text { Resting state } \\
\text { fMRI }\end{array}$ & $\begin{array}{l}\text { Out of six connectivity } \\
\text { pairs, four significantly } \\
\text { changed (normalised) } \\
\text { after the exercise } \\
\text { intervention: (1) Insula } \\
\text { - S1/M1 ( } p=0.0017 \text { ), } \\
\text { (2) Supr. Gyr. - S1/M1 } \\
\text { (p=0.0081), (3) Supr. } \\
\text { Gyr. - inferior PFC } \\
\text { (p=0.0053), (4) Supr. } \\
\text { Gyr. - cerebellum } \\
\text { (p=0.0033) }\end{array}$ & $\begin{array}{l}\text { FIQ: sign } \\
\text { improvement } \\
\text { ( } p=0.04 \text {, effect } \\
\text { size=0.53 (medium)). } \\
\text { SF-36 BP: no } \\
\text { change ( } p=0.98) . \\
\text { Changes in } \\
\text { functional } \\
\text { connectivity due to } \\
\text { physical exercise } \\
\text { were not correlated } \\
\text { with FIQ and SF-36 } \\
\text { BP scores (all } r<0.5) \text {. }\end{array}$ & $\begin{array}{l}\text { 15-week exercise } \\
\text { programme including } \\
\text { aerobic, isometric, } \\
\text { concentric, non- } \\
\text { concentric and } \\
\text { stretching exercises. } \\
\text { Two sessions a week of } \\
60 \text { min each. }\end{array}$ \\
\hline Martinsen et al ${ }^{45}$ & $\begin{array}{l}\text { Chronic } \\
\text { fibromyalgia, } n=19 \\
\text { (19 female) }\end{array}$ & $\begin{array}{l}\text { fMRI with } \\
\text { Stroop Colour } \\
\text { Word Test }\end{array}$ & $\begin{array}{l}\text { Postexercise, a } \\
\text { significant change } \\
\text { in activation of the } \\
\text { bilateral amygdala } \\
(p<0.001) \text { was found. }\end{array}$ & $\begin{array}{l}\text { FIQ: significant } \\
\text { decreased }(p=0.048) \\
\text { SF-36-PCS: } \\
\text { Intervention effect } \\
(p=0.048)\end{array}$ & $\begin{array}{l}\text { 15-week exercise } \\
\text { programme including } \\
\text { resistance exercises. } \\
\text { Two sessions a week of } \\
60 \text { min each. }\end{array}$ \\
\hline Micalos et al ${ }^{46}$ & $\begin{array}{l}\text { Chronic pain, } \\
\text { including } \\
\text { fibromyalgia }(n=8) \text {, } \\
\text { low back pain }(n=2) \text {, } \\
\text { complex regional } \\
\text { pain syndrome } \\
(n=1), n=11 \text { ( } 9 \\
\text { female) }\end{array}$ & $\mathrm{fMRI}$ & $\begin{array}{l}\text { Exercise-induced } \\
\text { significant change } \\
\text { in activation of the } \\
\text { thalamus }(p=0.04) \text {. }\end{array}$ & $\begin{array}{l}\text { MPQ only measured } \\
\text { at baseline, no } \\
\text { change score } \\
\text { available. }\end{array}$ & $\begin{array}{l}\text { 12-week exercise } \\
\text { programme including } \\
\text { aerobic exercises. Two } \\
\text { sessions a week of } \\
20 \text { min each. }\end{array}$ \\
\hline
\end{tabular}

BP, bodily pain; FIQ, Fibromyalgia Impact Questionnaire; fMRI, functional MRI; M1, primary motor cortex; MPQ, McGill Pain Questionnaire; PCS, Physical Component Score; PFC, prefrontal cortex; S1, primary somatosensory cortex; SF-36, Short Form-36; Supr. Gyr., supramarginal gyrus.

rs-fMRI and fMRI with Stroop Colour Word Test ${ }^{45}$ and fMRI with painful stimulus. ${ }^{436}$ An overview of the quality assessment is presented in table 2. All studies were deemed at high risk of bias with an inter-rater agreement for this assessment of $100 \%$. None of the studies reported assessor blinding, there is potential for confounding of the effects of the interventions, and for all studies the included sample size was small. Three studies $(75 \%)$ reported changes in outcome measures from before to after the intervention.

\section{Exercise and brain characteristics in chronic pain}

In a comparison of nine individuals with FM and nine pain-free controls, Ellingson et $a t^{43}$ found significantly higher activation levels bilaterally in the anterior insula in those with FM following one aerobic exercise session, compared with following quiet rest. Participants with FM demonstrated less activity in the left dorsolateral prefrontal cortex following quiet rest compared with postexercise, and also compared with pain-free controls following either quiet rest or exercise. The control group demonstrated greater activation in the right parietal operculum and the right pre/postcentral gyrus following exercise compared with quiet rest. Following the aerobic exercise session, patients with FM showed significantly decreased pain intensity (McGill Pain Questionnaire (MPQ, 0-100), Cohen's d=0.39).

A comparison between individuals with FM and healthy controls $^{44}$ demonstrated significant differences between four out of six resting state functional connectivity pairs at baseline. Following 15 weeks of combined aerobic and strengthening exercise training, functional connectivity in individuals with FM increased for three connectivity pairs (insula-primary sensory motor areas, $\mathrm{p}=0.0017$; supramarginal gyrus-primary sensory motor areas, $\mathrm{p}=0.0081$; supramarginal gyrus-inferior prefrontal cortex, $\mathrm{p}=0.0053$ ), and decreased for one connectivity pair (supramarginal gyrus-cerebellum, $\mathrm{p}=0.0033$ ) (all Bonferroni-adjusted significance level $\alpha=0.0083$ ). When compared with pre-post exercise changes in functional connectivity in healthy controls, only the magnitude of 
Table 2 Methodological quality of included studies $(n=4)$, assessed on the Cochrane Collaboration's Risk of Bias In NonRandomised Studies tool

\section{Ellingson et Flodin et Martinsen et Micalos et}

$a l^{43} \quad a l^{44} \quad a l^{45} \quad a l^{46}$

\section{Confounding}

1.1 Is there potential for confounding of the effect of intervention in Yes this study?

$\begin{array}{lllll}\text { 1.2 Was the analysis based on splitting participants' follow-up time } & \text { No } & \text { No } & \text { No } & \text { No } \\ \text { according to intervention received? } & \text { No } & \text { No } & \text { No } & \text { No } \\ \begin{array}{l}\text { 1.4 Did the authors use an appropriate analysis method that } \\ \text { controlled for all the important confounding domains? }\end{array} & & \text { No } & \text { No } & \text { No } \\ \begin{array}{l}\text { 1.6 Did the authors control for any postintervention variables that } \\ \text { could have been affected by the intervention? }\end{array} & \text { No } & & \end{array}$

2. Bias in selection of participants

\begin{tabular}{|c|c|c|c|c|}
\hline $\begin{array}{l}2.1 \text { Was selection of participants into the study (or into the analysis) } \\
\text { based on participant characteristics observed after the start of } \\
\text { intervention? }\end{array}$ & No & No & No & No \\
\hline $\begin{array}{l}2.4 \text { Do start of follow-up and start of intervention coincide for most } \\
\text { participants? }\end{array}$ & Yes & Yes & Yes & Yes \\
\hline
\end{tabular}
participants?

3. Bias in classification of interventions

$\begin{array}{lllll}\text { 3.1 Were intervention groups clearly defined } & \text { Yes } & \text { Yes } & \text { Yes } & \text { Yes } \\ \begin{array}{l}\text { 3.2 Was the information used to define intervention groups recorded } \\ \text { at the start of the interventions? }\end{array} & \text { Yes } & \text { Yes } & \text { Yes } \\ \begin{array}{l}\text { 3.3 Could classification of intervention status have been affected by } \\ \text { knowledge of the outcome or risk of the outcome? }\end{array} & \text { Yes } & \text { Yes } & \text { Yes } \\ \begin{array}{l}\text { 4. Bias due to deviations from intended interventions } \\ \text { 4.1 Were there deviations from the intended intervention beyond }\end{array} & \text { No } & \text { No } & \text { No } & \text { No }\end{array}$
what would be expected in usual practice?

\section{Bias due to missing data}

\begin{tabular}{|c|c|c|c|c|}
\hline 5.1 Were outcome data available for all, or nearly all, participants? & Yes & Yes & Yes & Yes \\
\hline $\begin{array}{l}5.2 \text { Were participants excluded due to missing data on intervention } \\
\text { status? }\end{array}$ & No & Yes & Yes & No \\
\hline $\begin{array}{l}5.3 \text { Were participants excluded due to missing data on other } \\
\text { variables needed for the analysis? }\end{array}$ & No & No & No & No \\
\hline $\begin{array}{l}\text { 5.4 Are the proportion of participants and reasons for missing data } \\
\text { similar across interventions? }\end{array}$ & N/A & No & No & $\mathrm{N} / \mathrm{A}$ \\
\hline $\begin{array}{l}5.5 \text { Is there evidence that results were robust to the presence of } \\
\text { missing data? }\end{array}$ & N/A & No & No & $\mathrm{N} / \mathrm{A}$ \\
\hline
\end{tabular}
missing data?

6. Bias in measurement of outcomes

\begin{tabular}{|c|c|c|c|c|}
\hline $\begin{array}{l}\text { 6.1 Could the outcome measure have been influenced by knowledge } \\
\text { of the intervention received? }\end{array}$ & No & No & No & No \\
\hline $\begin{array}{l}\text { 6.2 Were outcome assessors aware of the intervention received by } \\
\text { study participants? }\end{array}$ & Yes & Yes & Yes & Yes \\
\hline $\begin{array}{l}\text { 6.3 Were the methods of outcome assessment comparable across } \\
\text { intervention groups? }\end{array}$ & Yes & Yes & Yes & Yes \\
\hline $\begin{array}{l}\text { 6.4 Were any systematic errors in measurement of the outcome } \\
\text { related to intervention received? }\end{array}$ & No & No & No & No \\
\hline
\end{tabular}

7. Bias in selection of the reported result
7.1 Is the reported effect estimate likely to be selected, on the baseis No
No
No
No
of the results, from multiple outcome measurements within the
outcome domain?

Continued 


\begin{tabular}{|c|c|c|c|c|}
\hline & $\begin{array}{l}\text { Ellingson et } \\
\mathrm{al}^{43}\end{array}$ & $\begin{array}{l}\text { Flodin et } \\
\mathrm{al}^{44}\end{array}$ & $\begin{array}{l}\text { Martinsen et } \\
\mathrm{a} l^{45}\end{array}$ & $\begin{array}{l}\text { Micalos et } \\
\mathrm{al}^{46}\end{array}$ \\
\hline $\begin{array}{l}7.2 \text { Is the reported effect estimate likely to be selected, on the basis } \\
\text { of the results, from multiple analyses of the intervention-outcome } \\
\text { relationship? }\end{array}$ & No & No & No & No \\
\hline $\begin{array}{l}7.3 \text { Is the reported effect estimate likely to be selected, on the basis } \\
\text { of the results, from different subgroups? }\end{array}$ & No & No & No & No \\
\hline Overall risk of bias & High & High & High & High \\
\hline
\end{tabular}

Items that were not applicable were omitted from this table.

connectivity changes between the insula and primary sensory motor areas was significantly larger $(p=0.005)$ in individuals with FM. Although individuals with FM significantly improved on the Fibromyalgia Impact Questionnaire (FIQ, $\mathrm{p}=0.04$, effect size $\mathrm{r}=0.53$ ), these symptom improvements were not correlated to changes in brain connectivity. No changes in pain intensity were found following the exercise intervention (Short-Form 36 (SF-36) questionnaire, bodily pain, $\mathrm{p}=0.98$ ).

Martinsen $e t a t^{45}$ found significant baseline differences in Stroop test-related activation assessed with fMRI between individuals with FM and healthy controls in the cerebellum, caudate nucleus, insula and temporal lobe. Following 15 weeks of resistance exercise, increased activation was identified in the bilateral amygdala $(p<0.001)$ and right temporal lobe $(\mathrm{p}<0.001)$ of individuals with FM. No changes were found in the hippocampus nor in the caudate nucleus. Healthy individuals did not demonstrate any changes in activation between pre and postexercise. Following the exercise intervention, it was found that FM impacted less on daily activities (FIQ, $\mathrm{p}=0.048$ ), and improvements were found on the physical component score from the SF-36 $(\mathrm{p}=0.048)$. The correlation between these symptom improvements and Stroop test-related activation was not assessed. The SF-36 mental component score did not change following exercise.

In eight individuals with FM, two with back pain, and one with CRPS, Micalos et $a t^{46}$ identified changes in fMRI following 12 weeks of aerobic exercise intervention. Compared with controls, individuals with chronic pain demonstrated significantly larger changes in the thalamus $(p=0.04)$ after exercise, and a trend towards changes was found for the right superior temporal gyrus $(\mathrm{p}=0.06)$ and left caudate $(\mathrm{p}=0.21)$. Clinical outcomes including MPQ and SF-36 were only assessed at baseline and not post-exercise.

\section{DISCUSSION}

This systematic review identified four studies that reported the effects of exercise on brain characteristics in individuals with chronic musculoskeletal pain. None of these studies were RCTs and all were at high risk of bias. All studies reported significant changes in various brain fMRI outcomes following physical exercise, and three studies ${ }^{43-45}$ reported improvements in clinical outcomes. Due to the absence of randomisation into active intervention and control groups, evidence from these studies may not directly show the effects of exercise. Only one study ${ }^{44}$ assessed the correlation between outcomes and brain connectivity and reported that functional connectivity was not correlated with pain-related parameters. Insufficient data were available to investigate the differential effects of different exercise types, and meta-analysis was not possible due to heterogeneity in fMRI methods, patient groups and exercise types.

While numerous studies have demonstrated the presence of brain changes in chronic pain conditions, ${ }^{17-26}$ only four studies were identified that investigated the effects of exercise on the brain. In these four studies, a large number of regions of interest (ROIs) were analysed, with increased activation in only two regions (insula, primary sensory motor cortex) reported by more than one study. Increased activation in the insula was found in individuals with FM compared with controls, while the pre/postcentral gyrus showed higher activation levels in controls. ${ }^{43}$ Second, increased connectivity was found between the insula and primary sensorimotor cortex ${ }^{44}$ (located in the pre/postcentral gyrus, therefore considered the same ROI as Ellingson et al. ${ }^{43}$

Between-group differences found in the dorsolateral prefrontal cortex are likely to be clinically meaningful, as this region is strongly involved in pain modulation. ${ }^{47}$ The insula is a key region in the pain salience network, ${ }^{48}$ in pain processing patterns, ${ }^{49}$ and its activation levels have been found to positively correlate with pain intensity. ${ }^{50} \mathrm{~A}$ change in functional activation of the insula is therefore expected to have clinical consequences. This is further confirmed by a recent study in people with FM, in which connectivity between the insula and periaqueductal grey (PAG) was found to be associated with symptom severity. ${ }^{19}$ Changes in the activation of the primary sensorimotor cortex following physical exercise may be expected, as this region is responsible for controlling voluntary movement. Functional changes in this region have been reported in response to physical exercise in patients with mild to moderate hemiparesis following ischaemic stroke and were correlated with functional outcomes. ${ }^{51}$ 
In our review, only one study ${ }^{43}$ reported central changes following a single aerobic exercise session in people with chronic pain. The central effects of one bout of exercise in healthy participants have been reported by more studies. ${ }^{32}{ }^{33}$ In healthy adults, Rajab et $a \vec{l}^{32}$ found that one exercise session increased the functional connectivity of the precentral and postcentral gyri (similar to the increased activation in the right pre/postcentral gyrus found in the healthy control group by Ellingson et $a t^{43}$ ), secondary somatosensory area and thalamus. In athletes, the functional connectivity pathways consisting the PAG, pregenual anterior cingulate cortex and the middle insular cortex (all relevant to the descending pain systems) decreased after one training session. ${ }^{33}$

Three studies ${ }^{44-46}$ identified in this review reported interventions (aerobic, ${ }^{46}$ resistance $^{45}$ and combined ${ }^{44}$ ranging 12-15 weeks. Several studies have found brain alterations in non-adult chronic pain and pain-free populations following longer exercise interventions, of which some changes consistent with the three studies in this review. In overweight people, an 8-month aerobic exercise intervention significantly improved the spatial refinement of three functional connectivity networks (the default mode, cognitive control and motor networks). ${ }^{34}$ In children with CRPS, a 3-week multidisciplinary treatment (ie, a combination of physical exercise and behavioural training) enhanced in several connectivity pairs (amygdala with cortical, subcortical and cerebellar regions), and simultaneously reduced connectivity in other pairs (left amygdala with motor cortex, parietal lobe and cingulate cortex). ${ }^{52}$

The efficacy of exercise interventions for individuals with chronic pain may depend on the type and duration of exercise, ${ }^{37}$ and on the chronic pain condition. ${ }^{35}$ Therefore, a secondary aim of this study was to investigate whether different types and dosages of exercise interventions may exert different central effects. Due to the small number of eligible studies, a comparison of the magnitude of effects of different types and durations of interventions was not possible. As overall observation, brain changes in the same ROIs (insula and primary sensorimotor cortex) were found following both short and long intervention durations.

Of the four studies included in this review, three ${ }^{43-45}$ reported improvements in clinical outcomes, however, only one study ${ }^{44}$ reported the correlation between these clinical outcomes and changes in brain function. Patients with FM were less restricted in daily activities ${ }^{44} 45$ and showed improved self-reported physical function but these changes were not correlated with changes in brain function. ${ }^{45} \mathrm{One}^{43}$ of the four studies found decreased pain intensity following exercise, whereas another study ${ }^{44}$ did not find these improvements. Micalos $e t a t^{46}$ assessed pain and disability only at baseline and not post-exercise, thus relationships between brain changes and self-reported outcomes were not evaluated. It is therefore premature to draw any conclusions regarding the direction or strength of the association between neurobiological characteristics and clinical outcomes. Since the different responses to exercise (hypoalgesia vs hyperalgesia) likely represent a central mechanism, ${ }^{53}$ including measures of EIH in additions to MRI may allow a better understanding of the clinical relevance of brain changes. ${ }^{44}$ Taking measures at multiple time points, rather than solely preexercise and postexercise, would allow for a more detailed investigation of the association between brain characteristics and clinical outcomes. ${ }^{22} 2829$

\section{Study limitations}

Only studies published in English were included, which could lead to missed relevant publications in other languages. All four included studies were nonrandomised studies of low quality. Pooling of data for meta-analysis was not possible due to study heterogeneity. Only one study ${ }^{44}$ identified ROIs a priori, whereas others may have reported whatever brain regions were found to change. This may have contributed to a wide range of regions reported, whereas justifying ROIs a priori (eg, in study protocols) may improve the consistency in reported outcomes. Additionally, different fMRI procedures were used, making comparison across studies difficult. Finally, the included studies used only functional imaging methods, while studies in other patient groups show structural (white matter) changes following physical exercise ${ }^{545}$ Further, there is no evidence available showing the effects of exercise on grey matter or brain biochemistry, both of which have been identified in chronic pain conditions. ${ }^{187}$ Future investigations could include assessments of structural (grey and white matter), functional (connectivity) and biochemical outcomes in order to provide a complete overview of the central effects. A key question in terms of clinical relevance is which exerciseinduced neurobiological changes may have positive effects on pain, that is, changes in which brain region(s) are associated with improved pain and/or disability. Due to the small sample sizes of the included studies, the results should be interpreted with caution. Future studies investigating the effects of exercise in individuals with chronic pain should aim to include a justifiable number of participants. Although sample sizes were small which may increase the chance of a type II error, ${ }^{56}$ all included studies indicate that exercise exerts brain changes. Thus, the magnitude of the central neurobiological effects of physical exercise may be underestimated. Further evidence is needed to confirm this in adequately powered studies.

\section{Conclusion}

Although substantial differences were found across studies in terms of the durations of exercise intervention, brain ROIs and fMRI procedures, four studies reported that physical exercise exerts central neurobiological alterations. None of these studies were RCTs and all were of low quality. Due to the absence of randomisation into intervention and control groups, it is unclear whether brain changes are the direct effect of the exercise interventions. 
While in three out of four studies, improved health outcomes were found following the exercise intervention, only one study investigated the association with brain changes, and no correlation was found.

Contributors RMJdZ conceived the content, wrote the paper and approved the final version. KC contributed and approved the final version of the paper. MS conceived the design of the paper and approved the final version of the manuscript.

Funding The authors have not declared a specific grant for this research from any funding agency in the public, commercial or not-for-profit sectors.

Competing interests None declared.

Patient consent for publication Not required.

Ethics approval Ethical approval was not required as data from published studies was used.

Provenance and peer review Not commissioned; externally peer reviewed.

Data availability statement All data relevant to the study are included in the article or uploaded as supplementary information.

Open access This is an open access article distributed in accordance with the Creative Commons Attribution Non Commercial (CC BY-NC 4.0) license, which permits others to distribute, remix, adapt, build upon this work non-commercially, and license their derivative works on different terms, provided the original work is properly cited, appropriate credit is given, any changes made indicated, and the use is non-commercial. See: http://creativecommons.org/licenses/by-nc/4.0/.

\section{ORCID iD}

Rutger M J de Zoete http://orcid.org/0000-0002-0273-3377

\section{REFERENCES}

1 Hurwitz EL, Randhawa K, Yu H, et al. The global spine care initiative: a summary of the global burden of low back and neck pain studies. Eur Spine J 2018;27:796-801.

2 Henderson JV, Harrison CM, Britt HC, et al. Prevalence, causes, severity, impact, and management of chronic pain in Australian general practice patients. Pain Med 2013;14:1346-61.

3 Johannes CB, Le TK, Zhou X, et al. The prevalence of chronic pain in United States adults: results of an Internet-based survey. J Pain 2010;11:1230-9.

4 Fayaz A, Croft P, Langford RM, et al. Prevalence of chronic pain in the UK: a systematic review and meta-analysis of population studies. BMJ Open 2016;6:e010364.

5 Blyth FM, March LM, Brnabic AJM, et al. Chronic pain and frequent use of health care. Pain 2004;111:51-8.

6 Freburger JK, Carey TS, Holmes GM, et al. Exercise prescription for chronic back or neck pain: who prescribes it? who gets it? what is prescribed? Arthritis Rheum 2009;61:192-200.

7 Häuser W, Thieme K, Turk DC. Guidelines on the management of fibromyalgia syndrome - A systematic review. Eur J Pain 2010;14:5-10.

8 Kadetoff $D$, Kosek $E$. The effects of static muscular contraction on blood pressure, heart rate, pain ratings and pressure pain thresholds in healthy individuals and patients with fibromyalgia. Eur $J$ Pain 2007;11:39-47.

9 Okumus M, Gokoglu F, Kocaoglu S, et al. Muscle performance in patients with fibromyalgia. Singapore Med J 2006;47:752-6.

10 Smith TO. How effective is physiotherapy in the treatment of complex regional pain syndrome type I? A review of the literature. Musculoskeletal Care 2005:3:181-200.

11 Fransen M, McConnell S, Bell M. Therapeutic exercise for people with osteoarthritis of the hip or knee. A systematic review. J Rheumatol 2002;29:1737-45.

12 Michaleff ZA, Maher CG, Lin C-WC, et al. Comprehensive physiotherapy exercise programme or advice for chronic whiplash (promise): a pragmatic randomised controlled trial. Lancet 2014;384:133-41.

13 Lamb SE, Gates S, Williams MA, et al. Emergency department treatments and physiotherapy for acute whiplash: a pragmatic, twostep, randomised controlled trial. The Lancet 2013;381:546-56.

14 May A. Chronic pain may change the structure of the brain. Pain 2008;137:7-15.

15 Apkarian VA, Hashmi JA, Baliki MN. Pain and the brain: specificity and plasticity of the brain in clinical chronic pain. Pain 2011;152:S49-64.
16 Henry DE, Chiodo AE, Yang W. Central nervous system reorganization in a variety of chronic pain states: a review. $P M \& R$ 2011;3:1116-25.

17 Baliki MN, Mansour AR, Baria AT, et al. Functional reorganization of the default mode network across chronic pain conditions. PLoS One 2014;9:e106133.

18 Geha PY, Baliki MN, Harden RN, et al. The brain in chronic CRPS pain: abnormal gray-white matter interactions in emotional and autonomic regions. Neuron 2008;60:570-81.

19 Pujol J, Macià D, Garcia-Fontanals A, et al. The contribution of sensory system functional connectivity reduction to clinical pain in fibromyalgia. Pain 2014;155:1492-503.

20 Henderson LA, Peck CC, Petersen ET, et al. Chronic pain: lost inhibition? J Neurosci 2013;33:7574-82.

21 Apkarian AVet al. Chronic back pain is associated with decreased prefrontal and thalamic gray matter density. $J$ Neurosci 2004;24:10410-5.

22 Seminowicz DA, Wideman TH, Naso L, et al. Effective treatment of chronic low back pain in humans reverses abnormal brain anatomy and function. $J$ Neurosci 2011;31:7540-50.

23 Lutz J, Jäger L, de Quervain D, et al. White and gray matter abnormalities in the brain of patients with fibromyalgia: a diffusion-tensor and volumetric imaging study. Arthritis Rheum 2008;58:3960-9.

24 Coppieters I, De Pauw R, Caeyenberghs K, et al. Differences in white matter structure and cortical thickness between patients with traumatic and idiopathic chronic neck pain: associations with cognition and pain modulation? Hum Brain Mapp 2018;39:1721-42.

25 Coppieters I, De Pauw R, Caeyenberghs K, et al. Decreased regional grey matter volume in women with chronic Whiplash-Associated disorders: relationships with cognitive deficits and disturbed pain processing. Pain Physician 2017;20:E1025-51.

26 Baliki MN, Petre B, Torbey S, et al. Corticostriatal functional connectivity predicts transition to chronic back pain. Nat Neurosci 2012;15:1117-9.

27 Serrano-Muñoz D, Galán-Arriero I, Ávila-Martín G, et al. Deficient inhibitory endogenous pain modulation correlates with periaqueductal gray matter metabolites during chronic whiplash injury. Clin J Pain 2019;35:668-77.

28 Baliki MN, Chialvo DR, Geha PY, et al. Chronic pain and the emotional brain: specific brain activity associated with spontaneous fluctuations of intensity of chronic back pain. $J$ Neurosci 2006;26:12165-73.

29 Fregni F, Potvin K, Silva D, et al. Clinical effects and brain metabolic correlates in non-invasive cortical neuromodulation for visceral pain. Eur J Pain 2011;15:53-60.

30 Erickson KI, Voss MW, Prakash RS, et al. Exercise training increases size of hippocampus and improves memory. Proc Natl Acad Sci U S A 2011;108:3017-22.

31 Veldsman M, Churilov L, Werden E, et al. Physical activity after stroke is associated with increased interhemispheric connectivity of the dorsal attention network. Neurorehabil Neural Repair 2017;31:157-67.

32 Rajab AS, Crane DE, Middleton LE, et al. A single session of exercise increases connectivity in sensorimotor-related brain networks: a resting-state fMRI study in young healthy adults. Front Hum Neurosci 2014;8:625.

33 Scheef L, Jankowski J, Daamen M, et al. An fMRI study on the acute effects of exercise on pain processing in trained athletes. Pain 2012:153:1702-14

34 Krafft CE, Pierce JE, Schwarz NF, et al. An eight month randomized controlled exercise intervention alters resting state synchrony in overweight children. Neuroscience 2014;256:445-55.

35 Naugle KM, Fillingim RB, Riley JL. A meta-analytic review of the hypoalgesic effects of exercise. J Pain 2012;13:1139-50.

36 Van Oosterwijck J, Nijs J, Meeus M, et al. Lack of endogenous pain inhibition during exercise in people with chronic whiplash associated disorders: an experimental study. J Pain 2012;13:242-54.

37 Smith A, Ritchie C, Pedler A, et al. Exercise induced hypoalgesia is elicited by isometric, but not aerobic exercise in individuals with chronic whiplash associated disorders. Scand J Pain 2017;15:14-21.

38 Meeus M, Roussel NA, Truijen S. Reduced pressure pain thresholds in response to exercise in chronic fatigue syndrome but not in chronic low back pain: an experimental study. J Rehabil Med 2010;42:884-90.

39 Staud R, Robinson ME, Price DD. Isometric exercise has opposite effects on central pain mechanisms in fibromyalgia patients compared to normal controls. Pain 2005;118:176-84.

40 Kregel J, Coppieters I, DePauw R, et al. Does conservative treatment change the brain in patients with chronic musculoskeletal pain? A systematic review. Pain Physician 2017;20:139-54. 
41 Moher D, Liberati A, Tetzlaff J, et al. Preferred reporting items for systematic reviews and meta-analyses: the PRISMA statement. PLoS Med 2009;6: $1000097-6$.

42 Sterne JAC, Hernán MA, Reeves BC, et al. ROBINS-I: a tool for assessing risk of bias in non-randomised studies of interventions. BMJ 2016;355:i4919.

43 Ellingson L, Stegner A, Schwabacher I, et al. Exercise strengthens central nervous system modulation of pain in fibromyalgia. Brain Sci 2016;6:8.

44 Flodin P, Martinsen S, Mannerkorpi K, et al. Normalization of aberrant resting state functional connectivity in fibromyalgia patients following a three month physical exercise therapy. Neuroimage 2015;9:134-9.

45 Martinsen S, Flodin P, Berrebi J, et al. The role of long-term physical exercise on performance and brain activation during the Stroop colour word task in fibromyalgia patients. Clin Physiol Funct Imaging 2018;38:508-16.

46 Micalos PS, Korgaonkar MS, Drinkwater E, et al. Cerebral responses to innocuous somatic pressure stimulation following aerobic exercise rehabilitation in chronic pain patients: a functional magnetic resonance imaging study. Int J Gen Med 2014;7:425-32.

47 Tracey I, Mantyh PW. The cerebral signature for pain perception and its modulation. Neuron 2007;55:377-91.

48 Wiech K, Lin C-s, Brodersen $\mathrm{KH}$, et al. Anterior insula integrates information about salience into perceptual decisions about pain. $J$ Neurosci 2010;30:16324-31.

49 Brooks JCW, Tracey I. The insula: a multidimensional integration site for pain. Pain 2007;128:1-2.
50 Bornhövd K, Quante M, Glauche V, et al. Painful stimuli evoke different stimulus-response functions in the amygdala, prefrontal, insula and somatosensory cortex: a single-trial fMRI study. Brain 2002;125:1326-36.

51 Johansen-Berg H, Dawes H, Guy C, et al. Correlation between motor improvements and altered fMRI activity after rehabilitative therapy. Brain 2002;125:2731-42.

52 Simons LE, Pielech M, Erpelding N, et al. The responsive amygdala: treatment-induced alterations in functional connectivity in pediatric complex regional pain syndrome. Pain 2014;155:1727-42.

53 Nijs J, Van Houdenhove B, Oostendorp RAB. Recognition of central sensitization in patients with musculoskeletal pain: application of pain neurophysiology in manual therapy practice. Man Ther 2010;15:135-41.

54 Polak P, Leddy JJ, Dwyer MG, et al. Diffusion tensor imaging alterations in patients with postconcussion syndrome undergoing exercise treatment: a pilot longitudinal study. J Head Trauma Rehabil 2015;30:E32-42.

55 Yuan W, Wade SL, Quatman-Yates C, et al. Structural connectivity related to persistent symptoms after mild TBI in adolescents and response to aerobic training: preliminary investigation. $J$ Head Trauma Rehabil 2017;32:378-84.

56 Freiman JA, Chalmers TC, Smith $\mathrm{H}$, et al. The importance of beta, the type II error and sample size in the design and interpretation of the randomized control trial. Survey of 71 "negative" trials. N Engl J Med 1978;299:690-4. 